\title{
A Facility Lighting Comparison Based on Energy Savings and Efficiency, Pollution Prevention and Life Cycle Assessment
}

\author{
Zonghua $\mathrm{Xu}$ \\ Department of Mechanical, Industrial and Manufacturing Engineering \\ University of Toledo, 2801 W. Bancroft Street, Toledo, OH, 43606 \\ Tel: 614-619-8190Ｅmail: Zonghua.Xu@ rockets.utoledo.edu
}

Neelnayana Mim Kalita

Department of Civil Engineering, University of Toledo 2801 W. Bancroft Street, Toledo, OH 43606

Tel: 914-536-1282Ｅmail address: nkalita@rockets.utoledo.edu

Matthew Franchetti

Department of Mechanical, Industrial and Manufacturing Engineering The University of Toledo, 2801 W. Bancroft Street, Toledo, OH, 43606 Tel:419-530-8051_Email: matthew.franchetti@ utoledo.edu

Ashok Kumar

Department of Civil Engineering, University of Toledo

2801 W. Bancroft Street, Toledo, OH 43606

Tel:419-530-8115 Email address: Ashok.Kumar@utoledo.edu

Received: July 30, 2016 Accepted: August 17, 2016

doi:10.5296/emsd.v5i2.9801 URL: http://dx.doi.org/10.5296/emsd.v5i2.9801 


\section{Abstract}

The objective of this study is to compare the energy efficiency, potential energy savings and the environmental impact among different lighting types-incandescent lamps, CFL (compact fluorescent light) lamps and LED (light-emitting diode) lamps in a manufacturing facility. Three different tools were applied: Energy Assessment Spreadsheet (EAS), Pollution Prevention (P2) tool and GaBi 6. EAS was used to calculate the energy savings, P2 tool was used for carbon footprint analysis, and GaBi was used for the life cycle assessment (LCA) in lightings' use phase. The results indicated a saving of over $\$ 21,000$ and a reduction of 151 MT $\mathrm{CO}_{2} \mathrm{e}$ (metric tons of $\mathrm{CO}_{2}$ equivalents) greenhouse gases (GHGs) using CFL in comparison to incandescent lamps. Approximately, $\$ 24,000$ could be saved and $170 \mathrm{MTCO}_{2} \mathrm{e}$ of GHGs could be reduced by using LED lamps instead of incandescent lamps every year for the operation phase of the facility. The environmental impact categories identified from the LCA in lighting use phase indicated that using incandescent lamps for the facility was much more harmful for the environment than using CFL and LED lamps. Additionally, the environmental impact from the use of LED lamps for the facility was less than that of CFL lamps.

Keywords: Lighting energy and efficiency, CFL/LED lamps, Pollution prevention, Life cycle assessment

\section{Introduction}

In the past few decades, the role of policies to promote the adoption of energy efficient technologies has increased considerably. Such technologies are of great importance due to the shortage of energy supply and numerous benefits such as reduction in the energy costs of buildings and the environmental impact as a result of using lesser energy. Currently, the global energy use contributed by buildings is about $40 \%$ of the total contribution (U.S. DOE, 2011), and the research by Ullah (1996) indicates that lighting systems consumed around $30 \%-40 \%$ of the total electricity used in commercial buildings. The U.S. Energy Information Administration (EIA) estimated that in the United States about 404 billion kilowatt hours $(\mathrm{kWh})$ of electricity were used for lighting by the residential and the commercial sectors in 2015. This accounts for about $10 \%$ of total US electricity consumption (U.S. DOE, 2016). The International Energy Agency has estimated that emissions of approximately 1900 MT $\mathrm{CO}_{2}$ is due to lighting consumptions per year, of which $80 \%$ are associated with electricity generation (Waide and Tanishima, 2006). Mahmood (2012) suggested that reducing the electricity consumption and improving end-use efficiency can reduce GHG emissions. Furthermore, U.S. DOE (2013) predicted that the total electricity demand will increase by $24 \%$ in household sector because of increase in total households by 2040.

Incandescent, CFL and LED lamps are most commonly used lighting fixtures for both residential and commercial purposes. Energy efficiency of a lighting fixture is based on emitted light (lumens) divided by power it draws (watts). Incandescent lamps convert only $1 \%$ to $5 \%$ of the electricity consumed into usable light (the maximum efficiency for a near white light is $408 \mathrm{~lm} / \mathrm{W}$ ). Fluorescents, and especially compact fluorescent lamps are actively promoted and their conversion efficiencies are much higher than that of incandescent lamps but are unlikely to grow much above $100 \mathrm{~lm} / \mathrm{W}$. LED has similar or better efficiency 
than CFL, and it is still far from reaching theoretical limits that have already constrained future improvements in incandescent and fluorescent lamps (Azevedo et al., 2009). Smil (2003) argued that the provision of illumination is one of the most promising areas for future improvement in energy efficiency. According to the articles, Unlocking the Power of Energy Efficiency in Buildings from Natural Resources Defense Council (2008) and California Long Term Energy Efficiency Strategic Plan adopted by the CPCU (2008), governments and electricity providers created subsidies for appliances that are proven to save energy. Nearly $80 \%$ of all energy efficiency subsidies have gone to CFLs accounting for more than 20 billion dollars in investment since 1970, thus, replacing inefficient lightings such as incandescent lamps (NRDC, 2008 and CPCU, 2008). Lim et al. (2012) suggested that LEDs, an emerging and unsubsidized technology, have the potential to save more energy than CFLs. LEDs produce better light and are less damaging to the environment. The energy cost of each lighting fixtures used in the facility was estimated using Energy Assessment Spreadsheet (EAS).

Pollution Prevention (P2) is any practice that reduces, eliminates, or prevents pollution at its source, has been the declared policy of the US since the passage of the Pollution Prevention Act of 1990 and it is gaining more and more importance at the international level within governments and industries (U.S. EPA, 2016a). According to Spivak et al. (2013), P2 has been practiced and studied over the last 25 years and the Pollution Prevention Act states that pollution should be prevented or reduced at the source. Pollution prevention assessments for facilities with and without Energy Star Certification studied by Velagapudi et al. in 2014 showed that lightings with energy star certification are more energy efficient and environmentally friendly. P2 tool developed by U.S. EPA was used in this project.

LCA is emerging as one of the most functional techniques to estimate the energy use and GHG emissions during the life cycle of a product or project which includes life stages such as raw materials extraction, manufacture, product or project use and end of life of products (Finnveden et. al., 2009). This study used GaBi 6 for the LCA analysis.

From the literature it is clear that during the lighting use phase, the CFL/LED lamps consumes lesser electricity than the traditional incandescent bulbs and produces lesser GHGs, as incandescent lamps have lower ratio between the luminous flux (in lumens) of light output to the input electric power (in watts). However, a study that focuses specifically on comparison among incandescent, CFL and LED lamps in a facility does not exist in published literature. This paper intends to compare the energy efficiency, potential energy savings and environmental impact for an industrial facility using different lighting fixtures (incandescent, CFL and LED lamps) in the state of Ohio in US.

\section{Methodology}

\subsection{Assessment Tools}

Three assessment tools (EAS, P2 tool, and GaBi) were used to perform the analysis. They are described in the following sections. 


\subsubsection{Energy Assessment Spreadsheet v1.0 (EAS)}

The Energy Assessment Spreadsheet (EAS) tool is a simple platform for compiling input data and carrying out needed mathematical operations, which is an imminent part of the energy assessment project. The EAS (UT, 2016) developed by The University of Toledo Air Pollution Research Group (APRG) has three sections: lighting, motors, and HVAC systems that account for the majority of industrial energy consumption. The lighting section is further divided into three subsections: input data, lighting cost, and lighting cost reductions. Inserting the wattage, quantity, and annual operating hours for each category of fixtures, along with the unit cost of energy automatically generates information about annual energy consumption and operational cost of all individual fixture types and their corresponding totals. The EAS tool was designed by the APRG at The University of Toledo, which can be conveniently used by industries to calculate the annual energy consumption of lightings, motors and HVAC systems.

\subsubsection{U.S. EPA’s P2 Tool}

According to FY 2014-2018 Strategic Plan of the U.S. EPA, four P2 program outcomes should be measured in an assessment. They are: reductions in hazardous releases and hazardous inputs (pounds), reductions in GHG releases (metric tons of $\mathrm{CO}_{2}$ : $\mathrm{MTCO}_{2} \mathrm{e}$ ), reduced water consumption (gallons), cost savings associated with reducing hazardous pounds, $\mathrm{MTCO}_{2} \mathrm{e}$, and water consumption. P2 tool is designed by the U.S. EPA in the EXCEL spreadsheet format to measure the environmental and economic performance resulting from pollution prevention activities. It includes three spreadsheets: P2 Cost Savings Calculator, Gallons to Pounds Converter and P2 GHG calculator, of which P2 Cost Savings Calculator and P2 GHG Calculator are used for the purpose of measurement in this study. They demonstrate a unique multimedia perspective in reducing GHG emissions and producing associated cost savings. The P2 Cost Savings Calculator assesses cost savings associated with a variety of factors such as: reduced costs for hazardous inputs, handling hazardous waste, reductions in air permitting fees, reduced charges for water usage, and electricity. P2 GHG Calculator calculates GHG emission reductions from electricity conservation, green energy, fuel and chemical substitutions, water conservation, and improved materials management. (U.S. EPA, 2016b)

\subsubsection{Life Cycle Assessment}

The LCA process is governed under ISO 14000, the series of international standards addressing environmental management. The LCA model in this paper was constructed using GaBi 6 software. The goal of this LCA study is to compare different lighting types (incandescent, CFL and LED lamps) in their impact on the environment due to the electricity consumption in their use phase in the facility, The functional unit is overall lighting service of all the lamps in the facility with yearly operation time of 2750 hours, which is the yearly electricity consumed using incandescent, CFL and LED lamps respectively, all three types of lamps provide with same lumens in different wattages in all the areas of the facility as it is illustrated on the background of the facility, and in this study only the use phase of incandescent, CFL and LED lamps is included, the production, disposal and distribution stages of the lamps are not included. The total yearly electricity consumed for each lighting 
technology (incandescent, CFL and LED lamps) is used as the input data (the energy consumption during use stage) for GaBi LCA analysis, which is obtained from the calculation assuming all the areas in the facility using three different lighting types respectively, and the lighting fixtures quantities and wattages required were collected through the audit in the facility. The life cycle impact assessment method for this analysis is CML method developed at the Leiden University, and the following environmental impact categories chosen in this study from the GaBi software database are: Global Warming Potential (GWP), Acidification Potential (AP), Eutrophication Potential (EP), Ozone Depletion Air (ODP), Photochemical Ozone Creation Potential (POCP) and Human Toxicity Potential (HTP).

\subsection{Background of the Facility}

The industrial facility considered for this study has grown to become one of the largest producer of bronze bearings in northwest, Ohio, US. It has been used as an example facility to compare the differences among incandescent, CFL and LED lamps in terms of energy efficiency and environmental impact. An energy assessment was conducted for this facility. The audit included a walk through survey where the number of lighting fixtures and wattage required in different areas were collected. The data on the wattage and quantity of bulbs are shown in Table 1. The EAS was used to calculate the cost of all the lighting fixtures yearly, on the assumption that machine shop and warehouse operating hours are 8.5, office areas operating hours are 11, the number of facility operation days per year is 250 and the cost of energy is $\$ 0.1 / \mathrm{kWh}$ for different lighting fixtures. Assuming that CFL and LED lamps used in the facility produce the same amount of lighting output as that of incandescent lamps in all areas of the facility. The lighting data of the incandescent lamps are presented in Table 1 . The data for CFL and LED lamps can be obtained through equivalent wattages and light output of incandescent lamps shown in Table 2. The CFL and LED bulbs data are presented in Tables 3 and 4. Table 2 shows the equivalent wattages and light output of incandescent, CFL and LED bulbs for wattage conversion in this study. These data have been obtained from a business website called Eartheasy and it displays solutions for sustainable living (Eartheasy, 2014). The 80-watt CFL lamps in Table 2 and the 42-watt LED lamps is converted from the 400-watt incandescent lamps in Table 1 assuming that they produce the same lumens. The cost of electricity for the incandescent, CFL and LED lamps were estimated using EAS. The P2 GHG Calculator and P2 Cost Calculator were used to determine the GHG reduction and money savings respectively. LCA for use phase of incandescent, CFL and LED lamps were carried out using the GaBi 6 software.

Table 1. Incandescent lamps data for the facility

\begin{tabular}{|c|c|c|c|c|}
\hline $\begin{array}{c}\text { Fixture } \\
\text { Type }\end{array}$ & Fixture Details & Wattage & Quantity(number of bulbs) & Operating Hours per Year \\
\hline A & $\begin{array}{c}\text { Incandescent lamps } \\
\text { Machine Shop }\end{array}$ & 400 & 155 & 2125 \\
\hline B & Incandescent lamps Warehouse & 400 & 66 & 2125 \\
\hline C & Incandescent lamps Office 1 & 40 & 168 & 2750 \\
\hline D & Incandescent lamps Office 2 & 150 & 101 & 2750 \\
\hline E & Incandescent lamps Office 3 & 100 & 93 & 2750 \\
\hline
\end{tabular}


Incandescent lightings were assumed to be used in the facility.

Table 2. Equivalent wattages and light output of Incandescent, CFL and LED bulbs (Eartheasy, 2014)

\begin{tabular}{|c|c|c|c|}
\hline Light output & Incandescent & CFL & LED \\
\hline Lumens & Watts & Watts & Watts \\
\hline 450 & 40 & $8-12$ & $4-5$ \\
\hline $750-900$ & 60 & $13-18$ & $6-8$ \\
\hline $1100-1300$ & $75-100$ & $18-22$ & $9-13$ \\
\hline $1600-1800$ & 100 & $23-30$ & $16-20$ \\
\hline $2600-2800$ & 150 & $30-55$ & $25-28$ \\
\hline
\end{tabular}

Table 3. CFL lamps data for the facility

\begin{tabular}{|l|l|l|l|l|}
\hline $\begin{array}{l}\text { Fixture } \\
\text { Type }\end{array}$ & Fixture Details & Wattage & $\begin{array}{l}\text { Quantity(number of the } \\
\text { bulbs) }\end{array}$ & $\begin{array}{l}\text { Operating Hours per } \\
\text { Year }\end{array}$ \\
\hline A & $\begin{array}{l}\text { Compact Fluorescent Lights (CFL) } \\
\text { Machine Shop }\end{array}$ & 80 & 155 & 2125 \\
\hline B & $\begin{array}{l}\text { Compact Fluorescent Lights (CFL) } \\
\text { Warehouse }\end{array}$ & 80 & 66 & 2125 \\
\hline C & $\begin{array}{l}\text { Compact Fluorescent Lights (CFL) } \\
\text { Office 1 }\end{array}$ & 10 & 168 & 2750 \\
\hline D & $\begin{array}{l}\text { Compact Fluorescent Lights (CFL) } \\
\text { Office 2 }\end{array}$ & 42.5 & 101 & 2750 \\
\hline E & $\begin{array}{l}\text { Compact Fluorescent Lights (CFL) } \\
\text { Office 3 }\end{array}$ & 26.5 & 93 & 2750 \\
\hline
\end{tabular}

CFL lamps were assumed to be used in the facility.

Table 4. LED lamps data for the facility

\begin{tabular}{|c|c|c|c|c|}
\hline Fixture Type & Fixture Details & Wattage & Quantity & $\begin{array}{c}\text { Operating Hours } \\
\text { per Year }\end{array}$ \\
\hline A & LED Machine Shop & 42 & 155 & 2125 \\
\hline $\mathrm{B}$ & LED Warehouse & 42 & 66 & 2125 \\
\hline $\mathrm{C}$ & LED Office 1 & 4.5 & 168 & 2750 \\
\hline $\mathrm{D}$ & LED Office 2 & 26.5 & 101 & 2750 \\
\hline $\mathrm{E}$ & LED Office 3 & 18 & 93 & 2750 \\
\hline
\end{tabular}

LED lamps were assumed to be used in the facility.

\section{Results}

\subsection{Energy Assessment Results}

The facility has 583 lighting fixtures as it is shown in Table 1. Table 5 shows that the electricity usage in all areas of the facility is $273568 \mathrm{kWh}$ assuming that all the lighting 


\section{Mll Macrothink}

fixtures are incandescent lamps. If CFL and LED lamps are assumed to be applied in all the areas, the electricity usage would be $60772 \mathrm{kWh}$ and $33767 \mathrm{kWh}$ respectively, which is shown in Table 6 and Table 7. These data are generated by performing comparative assessments with incandescent lamps in the facility. The total yearly cost savings for CFL and LED lamps are $\$ 21,280$ and $\$ 23,980$ in the facility respectively. The percentage cost reduction is $77.8 \%$ for CFL lamps and $87.7 \%$ for LED lamps, which is calculated by annual cost reduction divided by annual total cost for the facility assuming to use incandescent lamps. Also, a cost comparison of CFL with LED lamps at the facility shows that the total yearly cost saving can be around $\$ 3377$ with a $44.4 \%$ cost reduction rate, which can be calculated from Fig. 1 .

Table 5. Total cost per year for the facility using Incandescent lamps

\begin{tabular}{|l|l|l|l|l|l|}
\hline \multicolumn{7}{|l|}{ Lighting Cost } \\
\hline Enter Cost of Energy per kWh $=\$$ & $0.10 / \mathrm{kWh}$ \\
\hline Fixture Type & $\mathrm{A}$ & $\mathrm{B}$ & $\mathrm{C}$ & $\mathrm{D}$ & $\mathrm{E}$ \\
\hline Wattage & 400 & 400 & 40 & 150 & 100 \\
\hline Quantity & 155 & 66 & 168 & 101 & 93 \\
\hline Total Wattage & 62000 & 26400 & 6720 & 15150 & 9300 \\
\hline Total Hours / Year & 2125 & 2125 & 2750 & 2750 & 2750 \\
\hline $\mathrm{kWh} /$ Year & 131750 & 56100 & 18480 & 41663 & 25575 \\
\hline Cost / Year & 13175 & 5610 & 1848 & 4166.25 & 2558 \\
\hline Total kWh / Year $=$ & 273568 & & & \\
\hline Total Cost / Year $=$ & $\$ 27357$ & & & \\
\hline
\end{tabular}

The annual energy consumption for all lightings, operational cost of all individual fixture types and their corresponding totals were estimated assuming that the facility uses incandescent lamps.

Table 6. Total cost per year for the facility using CFL lamps

\begin{tabular}{|l|c|c|c|c|c|}
\hline \multicolumn{7}{|l|}{ Lighting Cost } \\
\hline Enter Cost of Energy per $\mathrm{kWh}=\$ \quad 0.10 / \mathrm{kWh}$ \\
\hline Fixture Type & $\mathrm{A}$ & $\mathrm{B}$ & $\mathrm{C}$ & $\mathrm{D}$ & $\mathrm{E}$ \\
\hline Wattage & 80 & 80 & 10 & 43 & 27 \\
\hline Quantity & 155 & 66 & 168 & 101 & 93 \\
\hline Total Wattage & 12400 & 5280 & 1680 & 4293 & 2465 \\
\hline Total Hours / Year & 2125 & 2125 & 2750 & 2750 & 2750 \\
\hline $\mathrm{kWh} /$ Year & 26350 & 11220 & 4620 & 11804 & 6777 \\
\hline Cost / Year & 2635 & 1122 & 462.00 & 1180 & 678 \\
\hline Total $\mathrm{kWh} /$ Year $=$ & 60772 & & & & \\
\hline Total Cost / Year $=$ & $\$ 6077$ & & & & \\
\hline
\end{tabular}

The annual energy consumption for all lightings, operational cost of all individual fixture types and their corresponding totals were estimated assuming that the facility uses CFL lamps. 
Table 7. Total cost per year for the facility using LED lamps

\begin{tabular}{|l|c|c|c|c|c|}
\hline \multicolumn{7}{|l|}{ Lighting Cost } \\
\hline Enter Cost of Energy per $\mathrm{kWh}=\$$ & $0.10 / \mathrm{kWh}$ \\
\hline Fixture Type & $\mathrm{A}$ & $\mathrm{B}$ & $\mathrm{C}$ & $\mathrm{D}$ & $\mathrm{E}$ \\
\hline Wattage & 42 & 42 & 5 & 27 & 18 \\
\hline Quantity & 155 & 66 & 168 & 101 & 93 \\
\hline Total Wattage & 6510 & 2772 & 756 & 2677 & 1674 \\
\hline Total Hours / Year & 2125 & 2125 & 2750 & 2750 & 2750 \\
\hline $\mathrm{kWh} /$ Year & 13834 & 5891 & 2079 & 7360 & 4604 \\
\hline Cost / Year & 1383 & 589 & 208 & 736 & 460 \\
\hline Total kWh / Year $=$ & 33767 & & & & \\
\hline Total Cost / Year $=$ & $\$ 3377$ & & & & \\
\hline
\end{tabular}

The annual energy consumption for all lightings, operational cost of all individual fixture types and their corresponding totals were estimated assuming that the facility uses LED lamps.

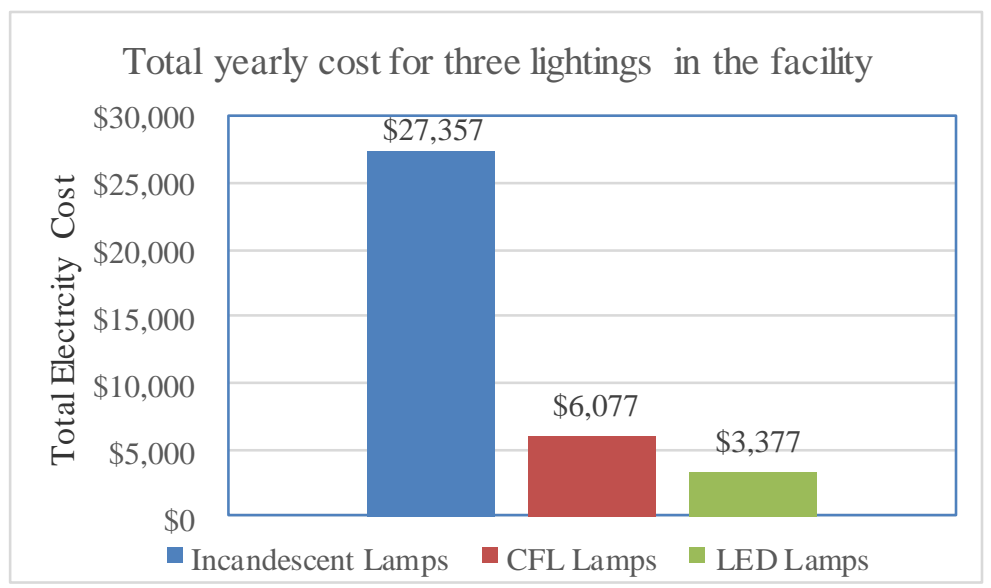

Figure 1 . Total yearly cost of different lighting types applied in the facility

\subsection{P2 Calculations}

As shown in Table 8 and Table 9, the P2 GHG Calculator and P2 Cost Calculator calculated the gas emission reduction and dollar savings using CFL and LED lamps instead of incandescent lamps respectively. The reduction of GHGs is $151 \mathrm{MTCO}_{2} \mathrm{e}$, with a savings of $\$ 21,280$ by using CFL lamps. The reduction of GHGs is $170 \mathrm{MTCO}_{2} \mathrm{e}$, with dollar savings of $\$ 23,980$ by using LED lamps. The total GHG produced from the use of incandescent lamps from the P2 calculation is $194 \mathrm{MTCO}_{2} \mathrm{e}$. Also 27,005 kWh of electricity is conserved and $\$ 2,701$ is saved when the LEDs are used compared with CFLs.

Table 8. P2 GHG Calculator output

\begin{tabular}{|c|c|c|c|c|}
\hline Light fixture & State or US (select) & Electricity conserved & Unit reported & GHG reduction $\left(\mathrm{MTCO}_{2} \mathrm{e}\right)$ \\
\hline CFL & U.S. & 212,80 & $\mathrm{kwh}$ & 150.80 \\
\hline LED & U.S. & 239,80 & $\mathrm{kwh}$ & 169.93 \\
\hline
\end{tabular}




\section{Macrothink \\ Environmental Management and Sustainable Development \\ ISSN 2164-7682 \\ 2016, Vol. 5, No. 2}

Table 9. P2 Cost Calculator output

\begin{tabular}{|c|c|c|c|c|c|}
\hline Light fixture & State or US (select) & Electricity conserved & Unit reported & Unit cost $(\$ /$ unit) & Dollar savings \\
\hline CFL & U.S. & 212,80 & $\mathrm{kWh}$ & $\$ 0.10$ & $\$ 21,279.60$ \\
\hline LED & U.S. & 239,80 & $\mathrm{kWh}$ & $\$ 0.10$ & $\$ 23,980.10$ \\
\hline
\end{tabular}

\subsection{Results from GaBi}

The LCA of the GHG emissions related to use phase of incandescent, CFL and LED lamps were identified using criteria under the method of CML 2001 in GaBi 6. In the LCA of lightings, only the use phase of the lightings in the facility were presented, as most of the environmental impact is related to the use stage due to the electric energy consumption during the life cycle of lamps. In fact, a study (Elijošiute et al., 2012) showed that for incandescent lamps, over $99 \%$ of $\mathrm{CO}_{2} \mathrm{e}$ emission comes from the generation of the electricity required to power the lamp at the users' sites and the rest comes from production and end of life phases, and for CFL lamps, over $91 \%$ of the $\mathrm{CO}_{2}$-equiv. emissions are generated during the use phase and the remaining comes from production and end of life phases. For LED lamps, less than $2 \%$ of the primary energy demand over the complete life cycle is required for manufacturing and $0.1 \%$ for end of life (Principi and Fioretti, 2014). The total yearly electricity consumed using incandescent, CFL and LED lamps is $273568 \mathrm{kWh}, 60772 \mathrm{kWh}$ and $33767 \mathrm{kWh}$ respectively for the facility, which is used as the input for GaBi software. The six environmental impact categories chosen in this study from the $\mathrm{GaBi}$ output related to the lighting electricity consumption are GWP, AP, EP, ODP, POCP and HTP. They are also illustrated in the handbook of LCA by Guinée (2002). Figures 2 through 5 show the numerical values for each impact categories for incandescent, CFL and LED lighting fixtures obtained from $\mathrm{GaBi}$ analysis.

The Global Warming Potential (GWP) is an index to measure the contribution to global warming of a substance that is released into the atmosphere. It was calculated for a time frame of 100 years, and it is expressed by $\mathrm{CO}_{2} \mathrm{e}$. As we can see from the Fig. 2, the GWP of the GHG emissions in terms of $\mathrm{CO}_{2} \mathrm{e}$ using incandescent lamps is 182 metric tons, which is 141.5 metric tons greater than that produced by using CFL lamps and 158.5 metric tons more than that produced by using LED lamps. The GWP of the GHGs produced from the use of LED lamps are18 metric tons lower than that of CFLs for the facility. These are close to the results obtained through $\mathrm{P} 2$ calculators. 


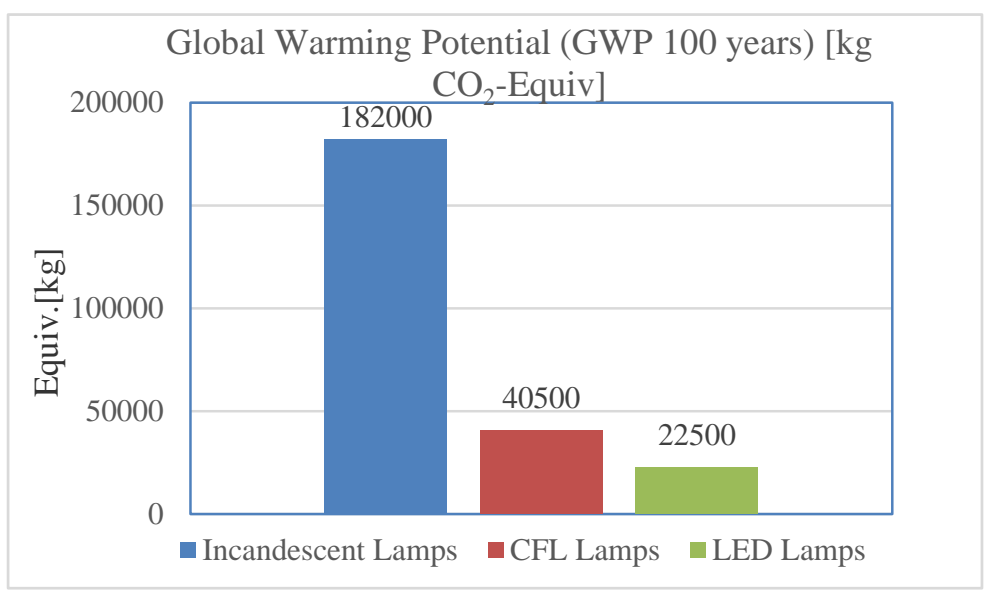

Figure 2. The characterization of the functional unit according to the environmental impact category of Global Warming Potential during LCA use phase

The Acidification Potential (AP) calculates the loss of the nutrient base (calcium, magnesium, potassium) in an ecosystem, and its replacement by acidic elements caused by atmospheric pollution. The AP here is dominated by nitrogen $\left(\mathrm{NO}_{2}\right)$ and sulfur dioxide $\left(\mathrm{SO}_{2}\right)$ emissions and is expressed by $\mathrm{SO}_{2} \mathrm{e}$, as it is shown in Fig. 3. The emission of $\mathrm{SO}_{2} \mathrm{e}$ using incandescent lamps is $427 \mathrm{~kg}$, which is $305 \mathrm{~kg}$ greater than that of the emissions from CFLs and $359.3 \mathrm{~kg}$ higher than that using LED lamps in the facility. The LED lamps show lower AP values for than CFL by a mass of $54.3 \mathrm{~kg}$.

The Human Toxicity Potential (HTP) assessment aims to estimate the negative impact of humans' processes. It is a calculated index that reflects the potential harm of a unit of chemical released into the environment, is based on both the inherent toxicity of a compound and its potential dose. It is expressed by DCB-Equivalents. As shown in Fig. 3, the emission of DCB-Equivalents using incandescent lamps is $8420 \mathrm{~kg}$, which is $6020 \mathrm{~kg}$ more than that using CFLs and $7080 \mathrm{~kg}$ more than that using LED lamps for the facility. The LED lamps show lower HTP values than CFL by a mass of $1060 \mathrm{~kg}$.

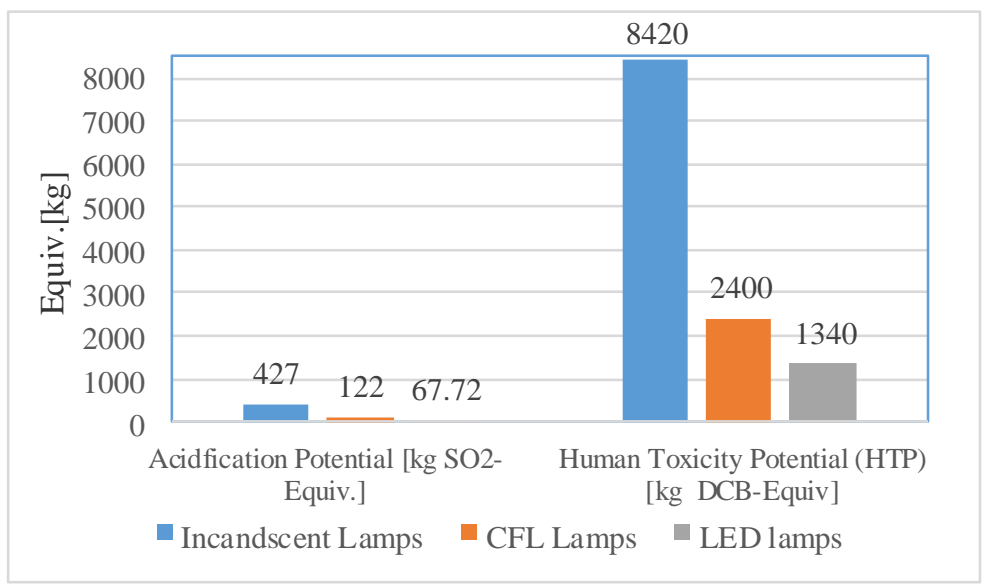

Figure 3. The characterization of the functional unit according to the environmental 
impact category of Acidification Potential and Human Toxicity Potential during LCA use phase

The Eutrophication potential (EP) is caused mainly by nitrogen oxide (NOx) emissions, followed by chemical oxygen demand and ammonia. It is expressed by phosphate $\left(\mathrm{PO}_{4}{ }^{3-}\right)$ equivalents. As shown in Fig. 4, the emission of $\mathrm{PO}_{4}{ }^{3-} \mathrm{e}$ using incandescent lamps is $26.3 \mathrm{~kg}$, which is $18.8 \mathrm{~kg}$ higher than that of CFL and $22.1 \mathrm{~kg}$ more than that of LEDs for the facility. The LED lamps show $3.3 \mathrm{~kg}$ lower eutrophication potential than CFL.

Photochemical ozone production (POCP) in the troposphere, also known as summer smog, is suspected to damage vegetation and material on the ground level. High concentrations of ozone are toxic to humans; it is expressed by ethylene equivalents. As it is shown in Fig. 4, the emission of Ethylene Equivalents using incandescent lamps is $26.9 \mathrm{~kg}$, which is $19.2 \mathrm{~kg}$ higher than that using CFLs and $22.6 \mathrm{~kg}$ more than that using LEDs for the facility. The LED lamps show $3.4 \mathrm{~kg}$ lower POCP values than CFL lamps.

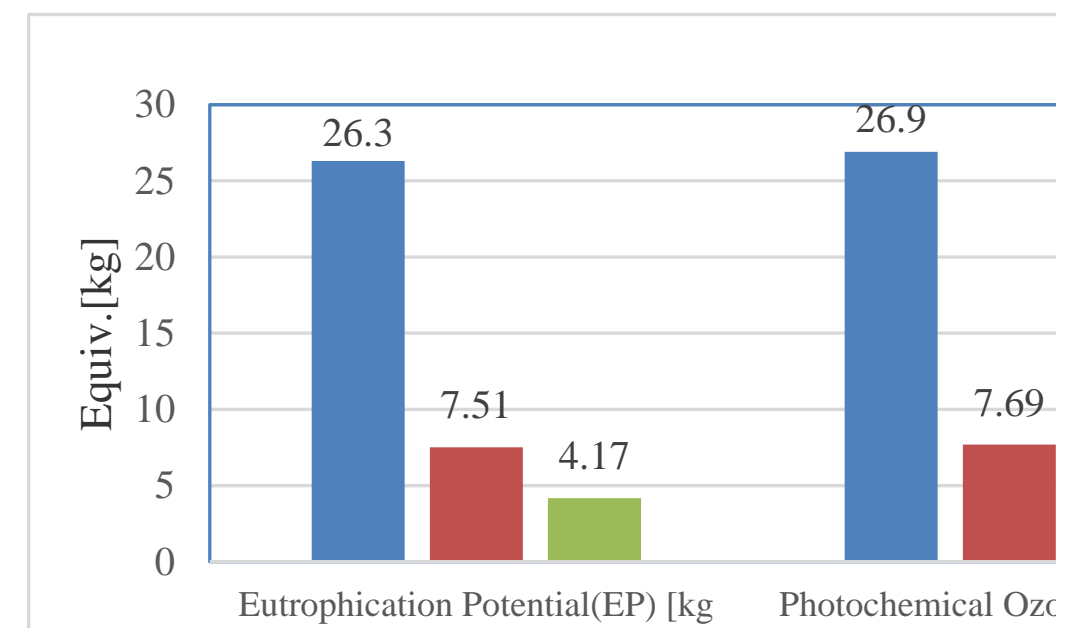

Figure 4. The characterization of the functional unit according to the environmental impact category of EP and POCP during LCA use phase

Ozone Depletion Potential (ODP) is a global measure of Ozone degradation in the stratosphere, such as Chloro-fluoro-carbons (CFCs). It is expressed by CFC 11e or R-11e. As shown in Fig. 5, the emission is significantly low and almost close to zero, while the emission using incandescent lamps is $52.2 \mathrm{mg}$, which is much higher than that of CFLs and LEDs for the facility. The LED lamps show lower ozone depletion potential than CFLs. 


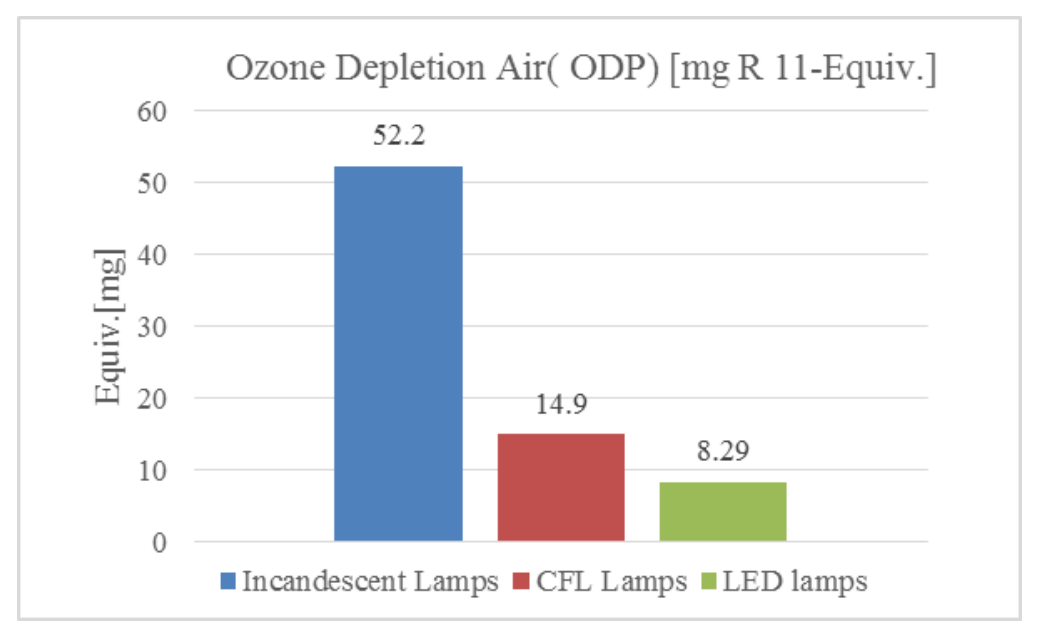

Figure 5. The characterization of the functional unit according to the environmental impact category of Ozone Depletion Potential during LCA use phase

\section{Discussion}

By running the hypothetical scenarios for the facility using incandescent, CFL and LED lamps in a machine shop, one warehouse and three offices, the EAS assessment showed that the LED lamps has the lowest yearly cost and best energy efficiency. The use of LEDs reduced the electricity consumption and cost reduction by $87.7 \%$ in comparison with incandescent lamps in the facility. The use of CFLs reduced the electricity and dollar consumption by $77.8 \%$ in contrast to incandescent lamps. The P2 assessment showed that LED lamps produced the lowest yearly $\mathrm{MTCO}_{2} \mathrm{e}$ emissions, and reduced GHG emissions by 87.7\% when compared with incandescent lamps. The CFL lamps reduced GHG emission by $77.8 \%$ in contrast to incandescent lamps. The outputs obtained from the GaBi software for average yearly operations in the facility is expressed in terms of six different environmental impact categories. The environmental impact for each category from the use of CFL and LED lamps at the facility are much lower than that obtained from using incandescent lamps. The resulting emissions from using LED lamps is lower than that of using CFL lamps. During the lighting use phase in the facility, the LED lamps would produce $87.6 \%$ less $\mathrm{CO}_{2} \mathrm{e}$ (GWP) and around $84.1 \%$ less $\mathrm{SO}_{2} \mathrm{e}$ (AP), Phosphate-Equiv. (EP), R11e. (ODP), Ethane-equiv. (POCP) and DCB-equiv. (HTP) than that generated by using incandescent lamps, and the LED lamps would produce around $44.4 \%$ less emissions of the six impact categories than that of CFL in the facility. The CO2e for GWP obtained from the LCA analysis is very close to the results gained from P2 assessment. The CO2e for GWP and the equivalent HTP emissions are much larger than emissions from the other impact categories, especially than ODP emissions, which is close to zero.

The results from P2 assessment and GaBi analyses showed that LED and CFL lamps use in the facility could cause much lower environmental impacts than that of incandescent lamps, and LED lamps cause a lower environmental impact than the CFL lamps, mainly as a result of different electricity wattage consumption during the facility's lighting operation. The luminous efficiency of the lamps is the factor that affects the results most in reducing 
electricity cost and impact on the environment during lighting function stage.

The assessment carried out in this study has many limitations. The equivalent wattages and light output of incandescent, CFL and LED bulbs shown in Table 2 was in reference to a business website. Such values may not be the actual values for the fixtures being used in the facility. The results of the LCA study were obtained for the use-phase of the lightings. This assumption was based on previous studies that showed the lighting use-phase dominates the entire life cycle of all the three lamps. However, the lifespan of the lightings and the cost of maintenance and installation should be investigated in future before upgrading the lighting services. Real-time emissions and the environmental impact potentials could vary in real life depending on the source of electricity production and may impact the conclusions due to uncertainty of the input data in $\mathrm{GaBi}$. Also, every software goes through updates with time to improve the results. Therefore, the users are advised to use current version.

\section{Conclusions}

The analysis conducted in this study shows that using CFL and LED lamps in the facility could be economically and environmentally beneficial in the lighting operation phase compared to incandescent. Additionally, the analyses show that LED lamps have better energy efficiency that reduces the electricity consumption, GHG emission and other hazardous emissions in the lighting use phase when a comparison is run between LED and CFL. During the study it was found that it is necessary for any facility to choose lightings with higher luminous efficacy (energy efficiency) in order to reduce electricity consumption and environmental impact from lighting electricity consumption.

\section{Acknowledgement}

The assessment was part of the Pollution Prevention Incentives for States (PPIS) Grant Program funded by the US Environmental Protection Agency (EPA). The opinions expressed in the paper are those of the authors. References in the papers to any specific commercial service or process, by trade name, trademark, manufacturer, or otherwise, do not necessarily imply their endorsement or recommendation by the U.S. EPA or the authors.

\section{References}

Azevedo, I. L., Morgan, M. G., \& Morgan, F. (2009). The transition to solid-state lighting. Proceedings of the IEEE, 97(3), 481-510. http://dx.doi.org/10.1109/JPROC.2009.2013058

California Public Utilities Commission (CPCU) (2008). California long term energy efficiency strategic plan. Section 2, 9.

Eartheasy (2014). LED light bulbs: Comparison charts. Retrieved from http://eartheasy.com/live_led_bulbs_comparison.html. Accessed June 12, 2016.

Elijošiutè, E., Balciukevičiūtè, J., \& Denafas, G. (2012). Life cycle assessment of compact fluorescent and incandescent lamps: comparative analysis. Environmental Research, Engineering and Management, 61(3), 65-72. http://dx.doi.org/10.5755/j01.erem.61.3.2425

Finnveden, G., Hauschild, M. Z., Ekvall, T., Guinée, J., Heijungs, R., Hellweg, S., \& Suh, S. 
(2009). Recent developments in life cycle assessment. Journal of Environmental Management, 91(1), 1-21. http://dx.doi.org/10.1016/j.jenvman.2009.06.018

Guinée, J. (2002). Handbook on Life Cycle Assessment: Operational Guide to the ISO Standards (Vol. 7). Springer Science \& Business Media. San Francisco, CA. http://dx.doi.org/10.1007/bf02978897

Lim, S. R., Kang, D., Ogunseitan, O. A., \& Schoenung, J. M. (2012). Potential environmental impacts from the metals in incandescent, compact fluorescent lamp (CFL), and light-emitting diode (LED) bulbs. Environmental Science \& Technology, 47(2), 1040-1047. http://dx.doi.org/10.1021/es302886m

Mahmood, A. (2012). Green Productivity: The carbon footprint and LED lighting technology, APO News. Retrieved from: http://www.apo-tokyo.org/publications/wp content/uploads/sites/5/2012_Sep-Oct_p4-5.pdf.

Natural Resources Defense Council (NDRC) (2008, December). Unlocking the power of energy efficiency in buildings. Retrieved on January 5, 2016 from: https://www.nrdc.org/sites/default/files/unlocking.pdf.

Principi, P. \& Fioretti, R. (2014). A comparative life cycle assessment of luminaires for general lighting for the office-compact fluorescent (CFL) vs light emitting diode (LED)-a case study. Journal of Cleaner Production, 83, 96-107. http://dx.doi.org/10.1016/j.jclepro.2014.07.031

Smil, V. (2005). Energy at the crossroads: global perspectives and uncertainties. MIT Press. Cambridge, Massachusetts.

Spivak, A., Kumar, A., \& Franchetti, M. (2013). Energy assessments for industrial complexes. Bentham Science Publishers. 217pp. http://dx.doi.org/10.2174/97816080570851130101

Ullah, M. B. (1996). International daylight measurement programme-Singapore data III: Building energy savings through daylighting. Lighting Research and Technology, 28(2), 83-87. http://dx.doi.org/10.1177/14771535960280020501

U.S. Department of Energy (2011). Energy efficiency and renewable energy. 2011 Buildings energy data book. Retrieved from: http://buildingsdatabook.eren.doe.gov/docs\%5CDataBooks\%5C2011_BEDB.pdf.

U.S. Department of Energy (2016). How much electricity is used for lighting in the United States? Retrieved from: http://www.eia.gov/tools/faqs/faq.cfm?id=99\&t=3.

U.S. Department of Energy (2013). Annual energy outlook 2013: With projections to 2040. Retrieved from: http://www.eia.gov/forecasts/aeo/pdf/0383(2013).pdf.

U.S. Environmental Protection Agency (2016a), Pollution Prevention (P2). Retrieved from http://www.epa.gov/p2/learn-about-pollution-prevention. Accessed July 23, 2016.

U.S. Environmental Protection Agency (2016b), Pollution prevention (P2). Retrieved from: http://www.epa.gov/p2/measuring-pollution-prevention. Accessed March 23, 2016. 


\section{Macrothink}

Environmental Management and Sustainable Development

ISSN 2164-7682 2016, Vol. 5, No. 2

UT (The University of Toledo) (2016), Pollution Prevention Tools. Retrieved from: http://www.eng.utoledo.edu/aprg/ppis/pptools.htm\#EA. Accessed May 26, 2016.

Velagapudi, S., Kumar, A., Spivak, A., \& Franchetti, M. (2014). Comparison of pollution prevention assessments for the facilities with and without energy star certification. Environmental Progress \& Sustainable Energy, 33(4), 1366-1372. http://dx.doi.org/10.1002/ep.11935

Waide, P., \& Tanishima, S. (2006). Light's labour's lost: policies for energy-efficient lighting. OECD Publishing.

\section{Copyright Disclaimer}

Copyright for this article is retained by the author(s), with first publication rights granted to the journal.

This is an open-access article distributed under the terms and conditions of the Creative Commons Attribution license (http://creativecommons.org/licenses/by/3.0/). 